\title{
Effect of 9 weeks continuous vs. interval aerobic training on plasma BDNF levels, aerobic fitness, cognitive capacity and quality of life among seniors with mild to moderate Alzheimer's disease: a randomized controlled trial
}

Lievyn Enette ${ }^{1 *}$ (D), Thomas Vogel ${ }^{1,2}$, Sylvie Merle ${ }^{3}$, Anna-Gaelle Valard-Guiguet ${ }^{4}$, Nathalie Ozier-Lafontaine ${ }^{5}$, Remi Neviere ${ }^{6}$, Claudia Leuly-Joncart ${ }^{7}$, Jean Luc Fanon ${ }^{7}$ and Pierre Olivier Lang ${ }^{8}$

\begin{abstract}
Background: Evidence suggests that aerobic-type training confers physical benefits and appears to contribute positively to brain health. This study aims to compare the effect of 9-weeks continuous (CAT) to interval aerobic training (IAT) on brain derived neurotrophic factor (BDNF) plasma level, aerobic fitness, cognitive performance, and quality of life among senior with Alzheimer's disease (AD).

Methods: 52 participants were randomly allocated into three groups (CAT $n=14$; IAT $n=17$; and Controls $n=21$ ). CAT and IAT consisted of 18 sessions of 30-min cycling, twice a week, over 9 weeks. During the same period, controls were engaged in interactive information sessions. Plasma BDNF level; aerobic fitness parameters (Metabolic equivalent task - METs; Maximal Tolerated Power - MTP); functional capacities (6-Minute Walk Test - 6MWT); cognitive performance (Mini Mental State Examination; Rey auditory verbal learning test; and digit span test) and quality of life (Quality Of Life of Alzheimer's Disease scale - QoL-AD) were measured in all participants at baseline and 9 weeks later. A third plasma BDNF level was quantified following a 4 weeks detraining.
\end{abstract}

Results: No significant change was measured in terms of plasma BDNF level and cognitive performance after interventions, in all groups compared to baseline. After 9 weeks, CAT and IAT significantly improved aerobic fitness parameters compared to controls (METs: +0.6 and +1.0 vs. +0.4 ; MTP: +16 watts and +20 watts vs. +10 watts; and functional capacities (6MWT: $+22 \mathrm{~m}$ and $+31 \mathrm{~m}$ vs. $-40 \mathrm{~m}$ ). Compared to controls, QoL-AD after CAT was improved (+ 2 points; $p=0.02)$.

Conclusions: Neither aerobic exercise modalities significantly modified plasma BDNF levels and cognitive performances. CAT and IAT enhanced aerobic fitness and functional capacities in AD patients and CAT their QoL.

Trial registration: ClinicalTrials.gov website (NCT02968875); registration date: 7 September 2016. "Retrospectively registered".

Keywords: Aerobic exercise, aerobic fitness, BDNF, Alzheimer's disease, cognitive performance, older adults

\footnotetext{
* Correspondence: enette.lievyn@gmail.com

${ }^{1}$ Research Laboratory Mitochondria, Oxidative stress and muscle resistance (MSP, EA-3072), Department of Physiology, Faculty of Medicine, Strasbourg University, Résidence La Yole, bat. B L'Etang Z'abricot, 97200 Strasbourg, France

Full list of author information is available at the end of the article
}

(c) The Author(s). 2020 Open Access This article is distributed under the terms of the Creative Commons Attribution 4.0 International License (http://creativecommons.org/licenses/by/4.0/), which permits unrestricted use, distribution, and reproduction in any medium, provided you give appropriate credit to the original author(s) and the source, provide a link to the Creative Commons license, and indicate if changes were made. The Creative Commons Public Domain Dedication waiver (http://creativecommons.org/publicdomain/zero/1.0/) applies to the data made available in this article, unless otherwise stated. 


\section{Introduction}

Alzheimer's disease (AD) is the most prevalent cause of cognitive impairment among the aging and aged population [1]. The hallmarks of this neurodegenerative disease are extracellular deposition of amyloid-ßeta (A $\beta$ ) plaques, intracellular neurofibrillary tangles (i.e., aggregates of hyper phosphorylated tau protein), and the progressive decline of the cholinergic activity in basal forebrain neurons [2]. By primarily affecting the hippocampus, the resulting cell death and brain atrophy progressively impact long-term memory and learning capacities, and at later stages, the patients' functional abilities to perform the simplest tasks of the daily life [3]. To date, only symptomatic pharmacological therapies modulating the acetylcholine or glutamate activity are available and none of them significantly slows down the course of the disease. Hence, developing strategies that could potentially maintain the highest possible cognitive performance, functional abilities, and quality of live (QoL) is important for altering AD progression [4]. Exercise including aerobic-type training such as continuous aerobic training (CAT) or interval aerobic training (IAT), is one valuable intervention to improve the brain health (i.e., structure and functions) in humans [5-7]. CAT is defined as continuous training performed at moderate intensity while IAT consists of periods high-intensity exercise alternated by period of relative recovery. Thus, as a complementary mean to the control of all common cardiovascular risk factors which are also implicated in AD physiopathology, improvement of cardiorespiratory fitness parameters is also associated with higher hippocampal volume, enhancement in functional capacities together with personal development $[8,9]$. In $\mathrm{AD}$, studies suggest that aerobic-type training might attenuate brain atrophy and symptoms by modulating the gene expression of nerve growth factor and neurotrophic factor. Those factors are important for neurogenesis, synaptogenesis, and neurotransmission [10-12]. By this ways, aerobic-type training might slow down the production of $\mathrm{A} \beta$ plaques and oxidative stress, which have deleterious effects on neurons activity in AD [13-15]. Of all neurotrophic factors, brain derived neurotrophic factor (BDNF) seems to be one of the most susceptible to be modulated by aerobic-type exercise [16, 17]. Member of the neurotrophin family, it is a growing and survival factor regulating the development and the maintenance of functional phenotype of neuronal cells, and the controls of the synaptic function and neuronal plasticity [18]. Acting via the tropomyosin-related kinase B (TrkB), BDNF has thus emerged as an important mediator of the memory process, the adaptability of the synaptic transmission, and more globally of the brain plasticity [18]. Although still unclear, several potential explanations have been suggested to explain the biological mechanism between aerobic-type exercise and BDNF pathways [19]. Warnn et al. reported that FNDC5 protein is released during exercise from skeletal muscle, inducing BDNF from hippocampus [20]. Other studies support that the vascular endothelium could be a other candidate source of syntheses of peripheral BDNF during exercise $[21,22]$. However, the exact impact of the intensity level as the underlying regulator explaining some of the benefits of functional and mental health outcomes is still controversial [23, 24].

Although evidence of the benefits of aerobic-type training on cardiorespiratory, cognitive performance, and QoL are consistent among healthy individuals (including seniors) [25], the respective impact of intensity (moderate vs. vigorous) and type (CAT vs. IAT) in mild to moderate AD patients remain unclear [26, 27]. Furthermore, the effect intensity and type of aerobic-type training modulates the BDNF level in this population has not yet been answered [28, 29]. Hereinafter are presented the results of the MARAE study ("Maladie d'Alzheimer et Réentrainement À l'Éffort" in French language) which analyzes the effect of CAT and IAT respectively on the plasma BDNF level, aerobic fitness parameters, walking capacity, cognitive performance, and QoL in seniors with mild to moderate AD. The feasibility of such training programs in this population was also an outcome.

\section{Materials and methods Study design}

The MARAE study was a randomized controlled trial conducted at the memory clinic of the University Hospital Centre of Martinique (Fort de France, France). All participants were recruited from April 19, 2016 to July 31, 2017 following an invitation to take part in the research on the benefits of exercise on general and mental health. Once included, participants were allocated to a training or control group (CG) with 2:1 ratio. Participants allocated to the training were secondarily randomized with a 1:1 ratio to either CAT or IAT program (Fig. 1). The allocation between the three groups was balanced as much as possible by considering blocks randomization of size 12. During the course of the study, members of the MARAE team supervised participants during training and CG period, and experienced specialists collected the primary (i.e., plasma BDNF concentration expressed in $\mathrm{pg} / \mathrm{ml}$ ) and secondary outcomes (i.e., aerobic fitness parameters, functional capacities, cognitive functions. and the participants' QoL). All study outcomes were measured and collected blind to the allocation group at baseline, after 9 weeks intervention period (referred as week-10) and only for plasma BDNF concentration, a third blood sample was collected 4 weeks after a detraining period, (referred as week-14 - Fig. 2). The experimental protocol was approved by the local ethic 


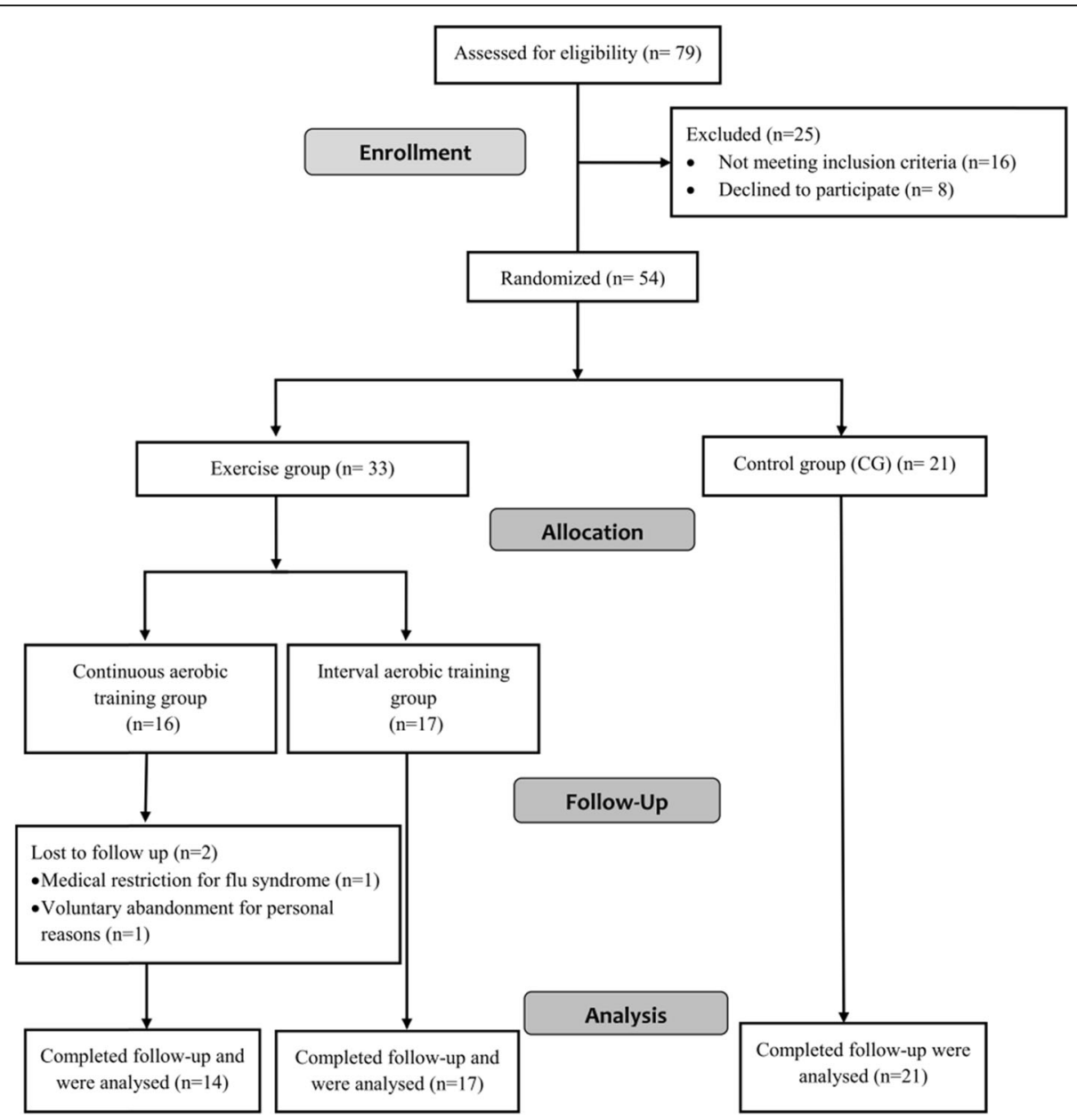

Fig. 1 Consort flow diagram of inclusion, randomization and follow-up including reasons for drop-out

committee (2015A00567-42 - www.cpp-soom3.u-bordeaux2.fr) and was registered on the ClinicalTrials.gov website (NCT02968875).

\section{Participants}

In order to detect a significant 30\% difference between post- and pre-training period in the plasma BDNF level (primary outcome) between training and control groups with a statistic power of $90 \%$, the enrolment goal of 20 participants by study group was calculated, taking into account the probability of $10 \%$ of dropout [30].

Volunteers among patients followed-up at the memory clinic were invited to participate without financial incentives. To be eligible, they had to be aged 60 years or over, functionally independent, able to exercise at moderate to high intensity level on cycle ergometers, and diagnosed with a mild to moderate $\mathrm{AD}$ according to the criteria of the revised version of the DSM (Diagnostic and Statistical Manual) fourth edition. At the time of inclusion, the Mini Mental State Examination (MMSE) score had to be 16/30 or over [31,32]. All volunteers, thus identified, completed a medical visit including a physical examination with the measurement of anthropometric parameters, resting heart rate (HR), systolic blood pressure (SBP) and diastolic blood pressure (DBP). A 12-lead electrocardiogram was also recorded. Body height was determined with a measuring rod, and total body weight and percentage of body fat were measured with Tanita weight and by bio-impedance respectively (Tanita ${ }^{\circ}, \mathrm{SC}^{2}$-240MA). Body mass index (BMI) was calculated as weight divided by height squared $(\mathrm{kg} /$ $\mathrm{m}^{2}$ ) and participants classified according to the World Health Organization classification as underweight $(<18.5$ $\mathrm{kg} / \mathrm{m}^{2}$ ), normal weight ( 18.5 to $24.9 \mathrm{~kg} / \mathrm{m}^{2}$ ), overweight ( 25 to $29.9 \mathrm{~kg} / \mathrm{m}^{2}$ ), and obese class I ( 30 to $34.9 \mathrm{~kg} / \mathrm{m}^{2}$ ) and II or over $\left(\geq 35 \mathrm{~kg} / \mathrm{m}^{2}\right)$. With the complete review of the current and past medical history, all conditions that contra-indicated aerobic training were identified (e.g., uncontrolled hypertension, severs musculoskeletal/musculotendinous disorders or fibromyalgia). In addition, individuals with sever cognitive impairment, undergoing 
chemotherapy for cancer, or suffering from any acute infection were not enrolled as well as people already engaged in any aerobic training program. The medication regimen was also recorded but not any specific treatment was considered as an inclusion or non-inclusion criteria.

During the medical interview, volunteers received information and instructions about the MARAE study, and the volunteer and his/her caregiver signed an informed consent before final inclusion. At the time of inclusion, volunteers were also requested to maintain their usual diet habits all along the duration of the study period. Participants could be excluded from the study protocol over time in case of the occurrence of any chest pain, hypertensive response to exercise (i.e., a difference between peak and baseline SBP of at least $60 \mathrm{mmHg}$ in men and 50 $\mathrm{mmHg}$ in women during exercise testing, or SBP exceeding $210 \mathrm{mmHg}$ in men and $190 \mathrm{mmHg}$ in women [33], any rhythm disorders, ST segment deviation, and/or respiratory problems during the baseline IMET.

\section{Primary outcome: circulating plasma BDNF level}

Blood samples were collected by venipuncture into EDTA tubes, at rest for at least $5 \mathrm{~min}$ and between 08.00 and 09.00 am after overnight fasting at baseline, at week-
10 (i.e., after, CAT, IAT, or information sessions for CG) and at week-14, following a 4 weeks detraining. Immediately, tubes were placed on ice, and centrifuged for 20 min at $3000 \mathrm{rpm}$ at $8^{\circ} \mathrm{C}$. The plasma was then collected into sterile $500 \mu \mathrm{L}$ microtubes and frozen at $-80^{\circ} \mathrm{C}$ until analyses (from 1 to 18 month according the participant). Plasma BDNF levels were measured by Enzyme-Linked Immunosorbent Assay (ELISA - BDNF Emax Immunoassay System, Promega, Madison, WI, USA) with appropriate dilution. All samples and standards were run in duplicate. When the BDNF value was out of the standard curve, a new measurement with a $1 / 4$ dilution was then run in duplicate. The means of the duplicates were used for subsequent statistical analyses. Each standard curve had a coefficient of determination about $\mathrm{r}^{2}=0.999$ [see Additional file 1 for further details].

\section{Secondary outcomes Aerobic fitness parameters}

In the three study groups, an incremental maximal exercise tests (IMET) supervised by an experienced cardiologist was carried out at baseline and at week-10 (Fig. 2). Before the IMET, HR, brachial SBP and DBP were measured seating after a rest of at least $5 \mathrm{~min}$. Participants

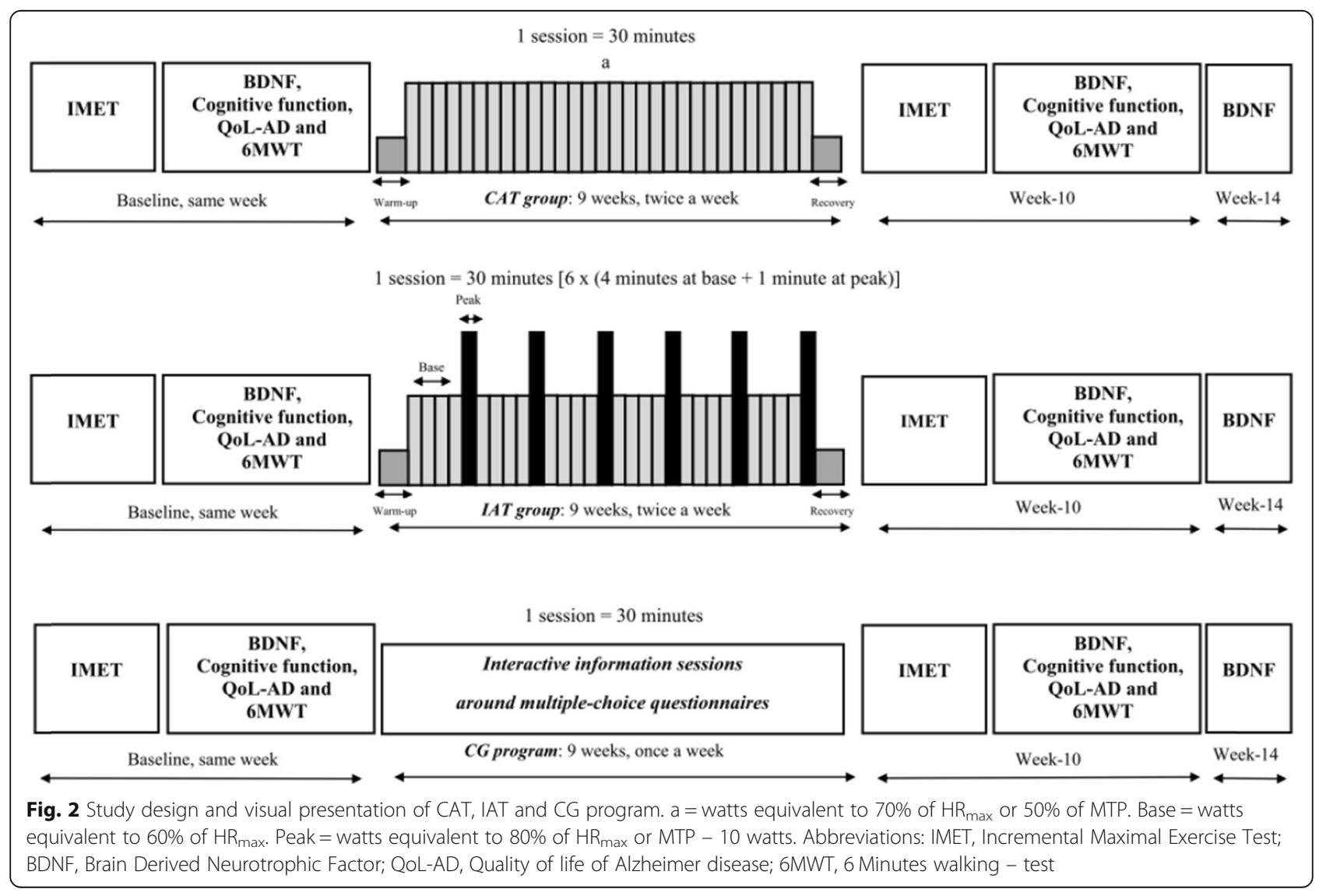


were then installed on an upright electronically braked cycle ergometer (Ergo-Line GmbH\&Co KG 800 s, Bitz, Germany). The IMET was carried out in an airconditioned room $\left(22.0 \pm 0.5^{\circ} \mathrm{C}\right)$, two hours after a light lunch. After a 2-min warm-up period at 10-25 watts, charge increments of 10 watts $\mathrm{min}^{-1}$ were used with at a pedaling frequency of $>60$ round per minute until to exhaustion, completed in 6-12 min [34]. IMET was terminated either because of cardiovascular exhaustion ( $\mathrm{HR}>85 \%$ of maximal HR theoretical $\left(\mathrm{HR}_{\max }=220\right.$ minus age)) and/or leg fatigue associated with a perceived exhaustion $>17$ on Borg scale $6-20$, requiring the end of the test [35]. Aerobic fitness capacity was expressed in maximal Metabolic Equivalent of Task (METs) and estimated based on the Maximal Tolerated Power (MTP) measured in watt using the following formula from the American College of Sports Medicine $($ METs $=(12,3 \times$ Watts $)+(3,5 \times$ weigh $) /($ weigh $\times 3,5))$ [36]. The MTP, METs and maximal HR (defined as heart rate peak - $\mathrm{HR}_{\text {peak }}$ ) were collected at the end of the test. During the IMET, HR was continuously monitored (Cardiovit CS-200, Schiller AG, Baar, Switzerland). For participants enrolled in the CAT and IAT groups, workloads determined from a percentage of $\mathrm{HR}_{\max }$ measured during the IMET, were considered to set the initial intensity target values for the first training sessions.

\section{Functional capacities}

A physiotherapist conducted a 6-min walking test (6MWT) at baseline and at week-10, in the CAT, IAT and CG (Fig. 2). The distance walked in meters was considered to evaluate the effect of the study intervention on functional capacities. The 6MWT was performed indoors along a flat firm surface (i.e., a $40 \mathrm{~m}$ hallway) according to standard recommendations [37].

\section{Cognitive performance tests}

In the three groups, an experienced neuropsychologist assessed the cognitive performance at baseline and at week-10 (Fig. 2). Validated tests were then considered to assess global cognition functioning (MMSE) [38, 39], episodic memory (Rey Auditory Verbal Learning Test RAVLT) [40] and working memory (Digit span test) [41] according to standard instructions. To measure the impact of the study interventions, the scores of the different sub-sets of the MMSE (i.e., orientation, registration and free recall, attention and calculation, language, and visual construction) were also analyzed individually.

\section{Quality of life assessment}

Finally, the QoL-AD scale [42] was used to assess the health-related QoL of all participants at baseline and at week-10. QoL-AD scale is a brief, 13-item measure, designed to provide both individual and proxy report which were calculated separately. This tool explores thirteen domains of the health-related QoL (i.e., physical health, energy, mood, living situation, memory, family, marriage, friends, self as a whole, ability to do chores, ability to do things for fun, money, and life as a whole). Each item was answered according to a Likert scale (from 1 - worst possible QoL to 4 - best possible QoL), for a total score between $13(\mathrm{~min})$ and $52(\max )$ [43]. According the standard instructions, to provide an assessment that may be more balanced than just either score alone, a single composite score combining the patient and caregiver ratings was calculated by multiplying the patient score by 2 , adding the caregiver score and dividing the sum by $3[42,43]$.

\section{Assessment of the feasibility of the training programs}

The feasibility of the training programs was evaluated according to $(i)$ the adherence rate defined as the number of sessions undertaken compared to the number of session scheduled, (ii) the level of exercise intensity reached (i.e., watts and perceived exertion), and (iii) the progressive enhancement (i.e., increase of workload over time). All adverse events such as muscles injuries, and muscle and joint pains occurring during the training program; and the number of participants dropped out and reasons why were also collected. Systematically, at the beginning of each session, all participants were questioned about the occurrence of any events since the last session and this until the end of the program.

\section{Additional data}

Socio-demographic characteristics of each participant together with data concerning the health status, drugs, and the ability to perform Activity of Daily Living (ADL) and Instrumental Activity of Daily Life (IADL) were also collected at baseline. In addition, the presence/absence of a depressive disorder was systematically screened according to the geriatric depressive symptoms scale (GDS) [44]. The inflammatory profile of participants was also evaluated with serum C-reactive protein (CRP) as marker, at baseline. The serum CRP assay was carried out by a venous blood sample, into an EDTA tube, and analyzed with an automatic COBAS 6000 analyzer by a nephelometric method (Roche Diagnostics $\mathrm{GmbH}$, Mannheim, Germany). The limit detection was $0.6 \mathrm{mg} / \mathrm{L}$.

\section{The aerobic training groups (CAT and IAT)}

As depicted by Fig. 2, CAT and IAT consisted of a 30-min cycling workout twice a week over 9 weeks (i.e. for 18 sessions in total) on an upright electronically braked cycle ergometer (Kettler GmbH \& Co KG E5, Kleinblittersdorf, Germany). Each session was started with a 2-min warmup and finalized with 1-min cool down. An experienced and trained physiotherapist supervised all the training 
sessions. HR was continuously monitored and automatically recorded (Polar H10, Kempele, Finland). SBP and DBP were also systematically measured (Omron M3 V4, Kyoto, Japan) before and after each session. In order to determine the appropriate intensity of CAT and IAT for each participant, we applied exercises protocols using either a fixed percentage of $\mathrm{HR}_{\max }$ or a fixed percentage of workload of MTP for participants with low fitness levels. This approach recommended to improve and maintain health in older adults was based on the recommendations of the American College of Sports Medicine and American Heart Association but also on previous investigations that assessed the feasibility of aerobic-type training in $\mathrm{AD}$ [45-47]. More specifically for CAT, participants performed $30 \mathrm{~min}$ on ergocycles at a power level equivalent to $70 \%$ of their $\mathrm{HR}_{\max }$ or $50 \%$ of MTP for participants who did not reach at least $85 \%$ of $\mathrm{HR}_{\max }$, measured during the IMET. From the second session, whenever the physiotherapist observed a decrease of 5 to 10 beats in HR or perceived exertion from 1 point (Borg 6-20) for the same workload after each session, the intensity was reevaluated and increased by approximately 5 to 10 watts at the next session in order to maintain the prescribed intensity.

For IAT, participants exercised $6 \times 1$ minute at a workload equivalent to $80 \%$ of $\mathrm{HR}_{\max }$ (for participants who did not reach at least $85 \%$ of $\mathrm{HR}_{\max }$ during the IMET) or at a workload equal to MTP inferior to 10 watts for others (PEAK). This was combined with $4 \mathrm{~min}$ of active recovery at a workload equivalent to $60 \% \mathrm{HR}_{\max }$ between intervals (BASE). As in CAT, any decrease in HR from 5 to 10 beats or perceived exertion from 1 point (Borg 6-20) for the same workload after each session, from the second session, resulted in an up adjustment approximately of 5 to 10 watts of the intensity of the load at "BASE" and "PEAK" at the next session [48]. During the exercise, HR values measured at the 28th and 30th minutes were considered "target values" for the entire program.

\section{Interactive information sessions}

In order to maintain their motivation [49], participants assigned to the CG were asked to attend interactive information sessions. They were also asked to not engage in any exercise training programs during all the study period (i.e. 14 weeks in total). Then, once a week, controls attended sessions detailing the health benefits of physical activity in seniors. These supervised sessions were structured with standardized multiple-choice questionnaires that participants had to discuss after together in an interactive way. In total, patients attended 9 sessions of 30-min each as shown in Fig. 2.

\section{Statistical analysis}

Analyses were computed with STATA (version 15.0) and $\mathrm{R}$ (version 3.3.2) software with a significant threshold set at $p=0.05$. Descriptive analyses were expressed for quantitative variables as median (Med), and interquartile range (IQR); for categorical variables, sample size was given. Specifically for BDNF values, the outlier-labeling rule was applied to define outliers in measures at baseline, at week-10 and at week-14. Observations that lie more than 2.2 times the interquartile range away from the nearest quartile were considered as outliers [50]. Two types of comparative analyses were computed. Thus, comparisons were computed between the three study groups (i.e., CAT, IAT and CG) and within each study group for pre- and post-intervention outcome measures respectively. The primary outcome measure was BDNF plasma $(\mathrm{pg} / \mathrm{ml})$. Secondary outcomes were aerobic fitness parameters (METs, MTP); distance walked at the 6MWT; global MMSE scores and sub-tests, RAVLT, and Digit span scores; and total of composite QoL-AD scores. Participants' characteristics at baseline were also compared according to the allocation group. Due to the small sample size and a majority of variables which did not meet the assumptions for normal distribution, we analyzed the data using nonparametric statistics. Thus, quantitative data were compared with Mann-Whitney or Kruskal-Wallis tests for inter-group comparisons and using the Wilcoxon test for paired samples for intra-group comparisons; for qualitative data the Fisher's exact test was considered. Specifically, to analyze the impact of some potential confounders variables (i.e., gender; age; MMSE score; aerobic fitness capacity in METs; intake of pro-cognitive treatment, storage duration of samples, intake of antidepressant drugs, chronic alcohol and/or tobacco consumption) on plasma BDNF values at baseline, a multivariable analysis of covariance (ANCOVA) was also considered. Chronic alcohol consumption was defined as consumption of more than two alcoholic beverages a day for men and one for women whereas smokers were defined as at least five cigarettes per day smoked since nine or more years $[51,52]$. Additionally, a comparison of plasma BDNF level between AD at mild stage (MMSE $\geq 21$ ) and moderate stage (MMSE $<21$ ) was computed. A Pearson's correlation coefficient was calculated to analyze the relationship between plasma BDNF level and cognitive performance according to MMSE, RAVLT, and digit span score.

\section{Results}

Out of the 79 volunteers who were willing to participate in the study, 54 were finally enrolled whom 52 completed the study protocol and follow-up. Reasons for non-inclusion and withdrawal are presented in Fig. 1. Participants aged 77.9 \pm 7.6 years (Min: 62 years; Max: 96 years) were for 31 assigned into one of the two training groups $(\mathrm{CAT}=14$; IAT $=17)$ and 21 were controls. 
Their characteristics at baseline are detailed in Table 1. No significant difference was measured between the 3 study groups except that individuals assigned into the two training groups were on average, lighter in body weight than controls due to a higher prevalence of underweight participants $(p=0.05)$. At baseline, individuals assigned into IAT group had a higher level of performance according to the METs value than controls $(p=0.03)$. Additionally, when participants $(n=52)$ were divided by disease stage (MMSE $\geq 21=18$; MMSE $<21=$ 34 ), plasma BDNF level was not significantly different, MMSE $\geq 21: 256.5 \mathrm{pg} / \mathrm{ml}, 106.9-449.7 \mathrm{pg} / \mathrm{ml}$; MMSE < 21: $253.6 \mathrm{pg} / \mathrm{ml}, 121-509.7 \mathrm{pg} / \mathrm{ml}-p=0.71$.

\section{Impact of exercise training on plasma BDNF response}

The effects of exercise modality and detraining period on plasma BDNF levels are shown in Fig. 3. No significant change was observed after 9 weeks of CAT $(282.7$ $\mathrm{pg} / \mathrm{ml}, 191-467.6)$ or IAT $(244.5 \mathrm{pg} / \mathrm{ml}, 180.6-380.7)$ compared to CG $(403.7 \mathrm{pg} / \mathrm{ml}, 205-516.9)$. There was also no significant difference between the two training groups. At week-14, no significant change was observed in CAT $(325.3 \mathrm{pg} / \mathrm{ml}, 135.6-683.3)$, IAT $(368 \mathrm{pg} / \mathrm{ml}$, 183-631) and controls $(265.9 \mathrm{pg} / \mathrm{ml}, 212.3-481.8) \mathrm{com}-$ pared to baseline values and week-10.. Similarly, when the same analysis was conducted with outliers, no significant change in plasma BDNF levels was observed after 9 weeks of CAT $(305.9 \mathrm{pg} / \mathrm{ml}, 191-499.6)$ or IAT $(244.5 \mathrm{pg} / \mathrm{ml}, 180.6-380.7)$ compared to CG $(424.9 \mathrm{pg} /$ $\mathrm{ml}, 206.6-515.8)$. At week-14, no significant change was observed in CAT $(325.3 \mathrm{pg} / \mathrm{ml}, 135.6-683.3)$, IAT (368 $\mathrm{pg} / \mathrm{ml}, 183-631)$ and controls $(287.8 \mathrm{pg} / \mathrm{ml}, 109-452.7)$ compared to baseline values and week-10. There was also no significant difference between the three study groups whatever the analysis method. The ANCOVA did not show any significant effect of the considered potential confounders for plasma BDNF level at baseline (i.e., gender, age, MMSE score, aerobic fitness in METs, storage duration of samples, pro-cognitive and antidepressive drugs). No chronic alcohol consumers and smokers were identified among participants. No correlation between plasma BDNF level and MMSE, RAVLT and digit span was found (all $p .>0.05$ ).

\section{Complementary analyses to identify determinants of plasma BDNF response}

In the view of the extreme variability of the plasma BDNF level response within the three study groups and between groups, complementary analyses were computed with the aim to identify explaining determinants of these individual's response after aerobic-type training. Due to the absence of significant difference between the CAT and IAT after training and detraining, the patients of these two groups were gathered. Thus, among participants, responders were defined as those in which, at least, a $10 \%$ increase of plasma BDNF level was measured between week-10 and baseline. This threshold was based on a previous studies that reported a small change of plasma BDNF level after aerobic-type training [53, 54]. Other participants were then considered as nonresponders. This was considered in the three study groups because BDNF level is influenced both by physical activity and social interactions $[55,56]$.

Among the 31 volunteers enrolled in training groups, 16 were responders $\left(\mathrm{CAT}_{\text {RESPONDER }}=9 ; \mathrm{IAT}_{\text {RESPONDER }}=\right.$ 7) and also 10 among the 21 controls. When responders and non-responders' medical, inflammation profile, cognitive characteristics, and fitness parameters collected at baseline were compared, no significant differences were observed [See Additional file 2]. Figure 4a and b show the evolution of BDNF levels over time in responders compared to non-responders according to the study group. Among responders, it was measured that in those assigned to the two training groups, BDNF response was maintained $(p=0.9)$ between week-10 and week-14 while in controls the plasma BDNF level seems decreased without reach the threshold of significance $(p=$ 0.07). In non-responders assigned to the aerobic training sessions, BDNF response also trended upwards between week-10 and week-14 but did not reach the threshold of significance $(p=0.06)$.

At baseline, non-responders had a higher plasma BDNF level compared to responders whatever the group of assignment $(p<0.01)$.

\section{Aerobic fitness and functional capacity}

The impact on aerobic fitness parameters is detailed in Table 2. Compared to control, after 9 weeks of training, the METs was improved by $14.3 \%$ in the CAT group (+ $0.6 \mathrm{MET} ; p=0.01)$ and $22.7 \%$ in the IAT group $(+1$ METs; $p=0.001)$. The MTP was enhanced by $30.8 \%$ $(p=0.009)$ and $40 \%(p=0.004)$ in CAT and IAT group, respectively. In term of functional capacity, the distance walked during the 6MWT was extended of $+4.7 \%(+28$ $\mathrm{m} ; p=0.005)$ and $+7.2 \%(+36 \mathrm{~m} ; p=0.007)$ in the CAT and IAT group, respectively. METs, MTP and the distance walked at the 6MWT remained statically unchanged among controls after 9 weeks. No significant difference was measured between IAT and CAT group for METs, MTP, and the distance walked at the 6MWT (all $p>0.05$ ).

\section{Cognitive performance}

The impacts of the study intervention groups on cognitive performance are presented in Table 3. Globally, there was no significant effect on global cognition and memory tests and sub-tests after the training period. Whilst a significant difference was found in MMSE score 
Table 1 Baseline demographic and clinical characteristics of participants by group

\begin{tabular}{|c|c|c|c|}
\hline Characteristic & CAT group, $n=14$ & IAT group, $n=17$ & Control group, $n=21$ \\
\hline Age (years) & $74(68-83)$ & $79(75-82)$ & $79(75-84)$ \\
\hline Female, $n$ & 11 & 11 & 11 \\
\hline Male, $n$ & 3 & 6 & 10 \\
\hline Height $(\mathrm{cm})$ & $167(163-171)$ & $163(160-170)$ & $170(162-175)$ \\
\hline Body weight(kg) & $65(60-71)$ & $60(52-67)^{a}$ & $72(60-77)^{a}$ \\
\hline Fat mass (\%) & $30(22-35)$ & $23(19-27)$ & $26(22-36)$ \\
\hline $\mathrm{BMI}\left(\mathrm{kg} / \mathrm{m}^{2}\right)$ & $23(21-26)$ & $22(20-24)$ & $23(21-26)$ \\
\hline \multicolumn{4}{|l|}{ BMl category } \\
\hline Underweight, $n$ & 1 & 2 & 0 \\
\hline Normal weight, $n$ & 9 & 13 & 13 \\
\hline Overweight, $n$ & 4 & 1 & 6 \\
\hline Obese, $n$ & 0 & 1 & 2 \\
\hline Nursing home residing, $n$ & 2 & 4 & 5 \\
\hline Home-living population, $n$ & 12 & 13 & 16 \\
\hline Education level (years) & $10(7-10)$ & $7(7-7)$ & $7(7-10)$ \\
\hline Alzheimer duration (years) & $2(1-4)$ & $2(1-5)$ & $6(3-6)$ \\
\hline \multicolumn{4}{|l|}{ Severity of dementia } \\
\hline Mild; MMSE $\geq 21$ & 5 & 2 & 11 \\
\hline Moderate; MMSE < 21 & 9 & 15 & 10 \\
\hline GDS, score & $0.1(0.2-0.5)$ & $0.5(0.6-1)$ & $0.6(0.3-0.9)$ \\
\hline$A D L$, score & $6(5.5-6)$ & $6(5.9-6)$ & $5.5(4.6-6)$ \\
\hline IADL, score & $4(3-6)$ & $4(3-6)$ & $3.5(2-5)$ \\
\hline \multicolumn{4}{|l|}{ Medicine } \\
\hline Antihypertensive treatment, $n$ & 8 & 12 & 13 \\
\hline Statins, $n$ & 2 & 4 & 2 \\
\hline Antidiabetic medication, $n$ & 2 & 4 & 4 \\
\hline Depression treatment, $n$ & 0 & 3 & 5 \\
\hline Anxiety treatment, $n$ & 1 & 2 & 2 \\
\hline Anti-psychotic, $n$ & 1 & 0 & 1 \\
\hline \multicolumn{4}{|l|}{ Anti - Alzheimer's treatment } \\
\hline Cholinesterase inhibitors, $n$ & 6 & 8 & 6 \\
\hline NMDA receptor antagonist, $n$ & 2 & 2 & 3 \\
\hline \multicolumn{4}{|l|}{ Comorbidities } \\
\hline Charlson, score & $1(1-1)$ & $2(1-2)$ & $1(1-2)$ \\
\hline Hypertension, $n$ & 8 & 12 & 13 \\
\hline Diabetes, $n$ & 2 & 4 & 4 \\
\hline Hypercholesterolemia, $n$ & 3 & 4 & 2 \\
\hline \multicolumn{4}{|l|}{ Inflammatory marker } \\
\hline C-reactive protein $(\mathrm{mg} / \mathrm{L})$ & $0.6(0.6-1)$ & $0.6(0.6-1.3)$ & $1(0.6-2)$ \\
\hline BDNFp (pg/ml) & $194.9(95.1-315)$ & $353.8(109-452.7)$ & $254(128.5-542.2)$ \\
\hline METS & $4.2(3.2-4.9)$ & $4.4(3.9-4.9)^{a}$ & $3.4(2.9-4.2)^{a}$ \\
\hline MTP & $52(42-60)$ & $50(50-66)$ & $40(35-70)$ \\
\hline$H R_{\text {peak }}$ (Beats per minute) & $124(116-141)$ & $120(113-126)$ & $112(106-120)$ \\
\hline Measured $H R_{\text {peak }} / \mathrm{HR}_{\max }(\%)$ & 87 & 85 & 81 \\
\hline
\end{tabular}


Table 1 Baseline demographic and clinical characteristics of participants by group (Continued)

\begin{tabular}{llll}
\hline Characteristic & CAT group, $n=14$ & IAT group, $n=17$ & Control group, $n=21$ \\
\hline RPE at HR peak & $18(17-18)$ & $17(17-18)$ & $17(17-18)$ \\
6MWT (meters) & $470(402-494)$ & $430(370-460)$ & $420(360-450)$ \\
MMSE score & $18(16-21)$ & $18(17-19)$ & $21(17-23)$ \\
RAVLT & $22(13-26)$ & $21(16-25)$ & $19(18-24)$ \\
Forward Digit Span & $5(3-6)$ & $4(4-5.3)$ & $5(4-7)$ \\
Backward Digit Span & $2(2-3)$ & $3(2-3)$ & $3(2-4)$ \\
QoL-AD composite & $34(32-36)$ & $34(32-35)$ & $32(29-34)$ \\
\hline
\end{tabular}

Median and range are provided unless otherwise indicated. ${ }^{\text {a }}$ : between group difference $(p<0.05)$ Abbreviations: $n=$ Number; BMI = Body Mass Index; Underweight $\mathrm{BMI}<18.5$; Normal weight $\mathrm{BMI}=18.5-24.9$; Overweight $\mathrm{BMI}=25-29$; Obese BMI > 30; MMSE = Mini-Mental Status Exam (maximum score $=30$ ); GDS = Geriatric disease scale: Score 0 to 4, score > 1 indicating high probability of depression; ADL = Activity of Daily Life, score 0 to 6 high score indicate more independence; $I A D L=$ Instrumental of Activity of Daily Life, score 0 to 8 high score indicate more independence; NMDA = N-methyl-D-aspartate; BDNFp: Plasma Brain derived neurotrophic factor; MET = Metabolic equivalent task; HR = Heart rate; RPE = Rating perceived exhaustion (Borg scale 6-20). 6MWT = 6 Minutes Walk Test; RAVLT: Rey Auditory Verbal learning Test, score 0 to 75 with higher score indicating better memory. QoL-AD: Quality of Life in Alzheimer's Disease, total score 13 to 52 with higher score indicating better quality of life. Equation: $\mathrm{HR}_{\max }($ beats $/ \mathrm{min})=220$ - age

between the two training groups (CAT: $+11.1 \%$ vs. IAT: $-5.6 \%-p=0.04$ ), no significant difference was measured for RAVLT, forward digit span and backward digit span from baseline to post-training (all $p>0.05$ ). We measured a decrease of attention and calculation in MMSE subtest scores in IAT group $(-50 \% ; p=0.03)$ and a decrease in MMSE score at the limit to significance threshold in CG $(-9.5 \% ; p=0.05)$. RAVLT and digit span forward -backward score remained statically unchanged among controls after interactive information sessions. No significant difference was observed between CG and the two-training group.

\section{Quality of life}

As shown in Table 4, the QoL-AD composite score within the CAT group was improved significantly (+ $5.9 \% ; p=0.008)$ compared to IAT participants and controls after intervention period. The difference between groups was in favor of CAT group compared to controls $(p=0.02)$. Two domains of the QoL-AD tool were significantly improved. They were humor $(p=+$ $50 \% ; p=0.02)$ and money $(+50 \% ; p=0.01)$. No significant difference was observed between the two-training group [See Additional file 3 for QoL-AD total score patient and caregiver].

\section{Feasibility and adverse events}

Among the 54 enrolled participants, only 2/54 did not complete the full study program. One because of a flulike illness episode and the second was injured during a domestic accident.

The 18 sessions composing the endurance training programs were followed by 49/52 participants for global adherence rate of $94.2 \%$. Two individuals did not

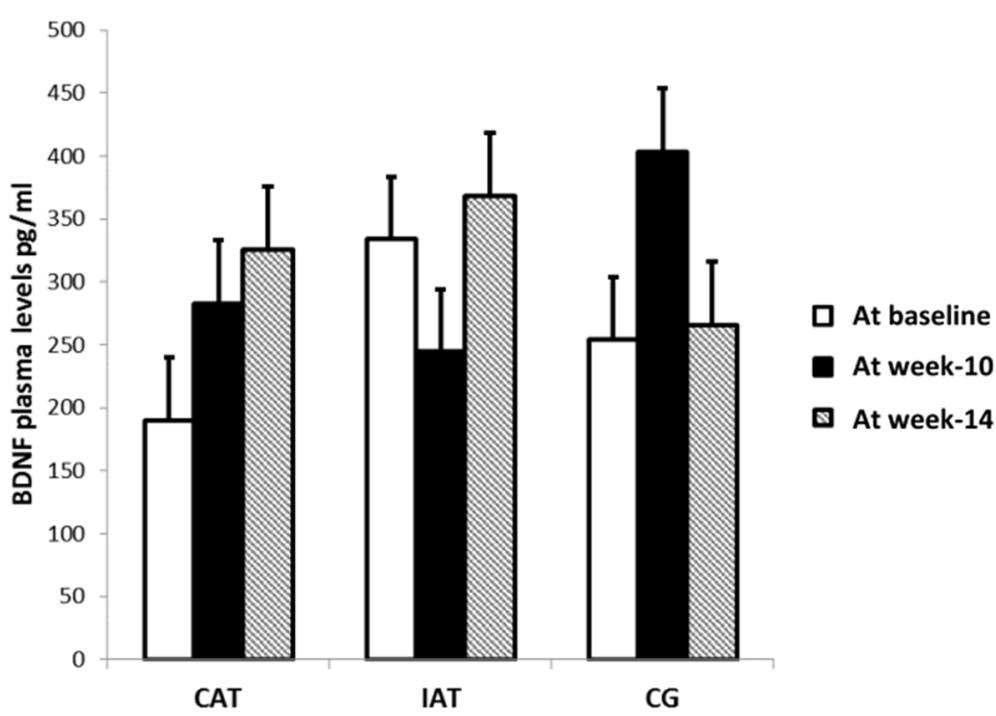

Fig. 3 Effect of 9 weeks of aerobic training and 4 weeks of detraining on BDNF plasma level 

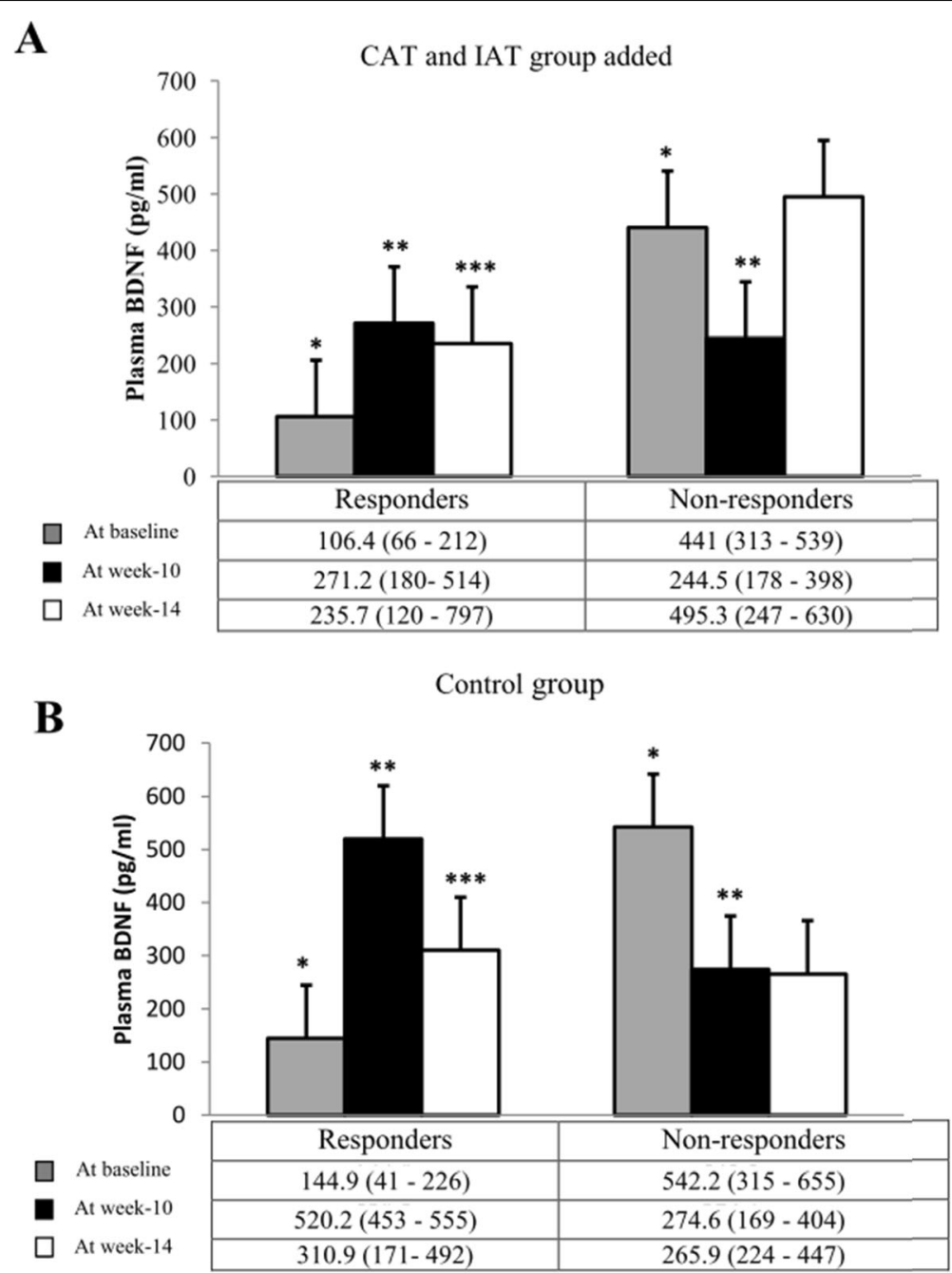

Fig. 4 At the bottom, exploratory analysis of plasma BDNF level after 9 weeks of training (week-10) and after a detraining period (week-14) for continuous aerobic (CAT) and interval aerobic training (IAT) group added and control group. Data are presented as median and interquartile range. At the top BDNF plasma level during study *Significant difference between responder and non-responders at baseline $(p<0.05)$; ** Significant difference between baseline and after 9 weeks $(p<0.05)$; ${ }^{* *}$ Significant difference between baseline and the detraining $(p<0.05)$

participate in 1 to $3 / 18$ sessions in the CAT group. One individual did not participate in $2 / 18$ sessions in the IAT group. In CAT, mean training intensity represented $76 \%$ of $\mathrm{HR}_{\max }$ and the workload went from 23 watts during the first training to 48 watts during the last one whereas in IAT, the starting workload was 21 watts (base) and 43 watts (peak), and increased up to 26 watts (base) and 77 watts (peak). The mean exercise intensity was $75 \%$ of $\mathrm{HR}_{\max }$. All patients were able to achieve the desired physical

Table 2 Effect of 9 weeks on aerobic fitness and functional capacities in different groups

\begin{tabular}{|c|c|c|c|c|c|c|}
\hline \multirow[t]{2}{*}{ Characteristic } & \multicolumn{2}{|c|}{ CAT group, $n=14$} & \multicolumn{2}{|c|}{ IAT group, $n=17$} & \multicolumn{2}{|c|}{ Control group, $n=21$} \\
\hline & Pre - Training & Post - Training & Pre - Training & Post - Training & Pre - Intervention & Post - Intervention \\
\hline METs & $4.2(3.2-4.9)$ & $4.8(4.2-5.9)^{* a}$ & $4.4(3.9-4.9)$ & $5.4(4.3-6.1)^{* b}$ & $3.4(2.9-4.2)$ & $3.9(2.8-4.5)^{a, b}$ \\
\hline $\begin{array}{l}\text { Maximal tolerated } \\
\text { Power (watts) }\end{array}$ & $52(42-60)$ & $68(65-79)^{* a}$ & $50(50-66)$ & $70(60-80)^{* b}$ & $40(35-70)$ & $50(35-70)^{a, b}$ \\
\hline $\begin{array}{l}\text { Distance 6MWT } \\
\text { (meters) }\end{array}$ & $470(402-494)$ & $492(465-526)^{*}$ & $430(370-460)$ & $461(420-530)^{*}$ & $420(360-450)$ & $380(320-475)$ \\
\hline
\end{tabular}

Median and rang are provided unless otherwise indicated, ${ }^{*}$ : intra group difference $(p<0.05) .{ }^{\mathrm{a}}:$ between group difference $(p<0.05),{ }^{\mathrm{b}}:$ between group difference $(p<0.05)$. Abbreviations: MET $=$ Metabolic equivalent task; $6 \mathrm{MWT}=6$ Minutes' Walk Test 
Table 3 Comparison of outcomes measure scores before and after the intervention in different groups

\begin{tabular}{|c|c|c|c|c|c|c|}
\hline \multirow[t]{2}{*}{ Variables } & \multicolumn{2}{|c|}{ CAT group, $n=14$} & \multicolumn{2}{|c|}{ IAT group, $n=17$} & \multicolumn{2}{|c|}{ Control group, $n=21$} \\
\hline & Pre - Training & Post - Training & Pre - Training & Post - Training & Pre - Intervention & Post - Intervention \\
\hline \multicolumn{7}{|l|}{ Global cognition } \\
\hline \multicolumn{7}{|l|}{ MMSE, Sub test: } \\
\hline Orientation & $4.5(4-6)$ & $6(4.3-7)$ & $5(4-6)$ & $5(3-7)$ & $7(4.8-8)$ & $5(4-7)$ \\
\hline Registration & $3(3-3)$ & $3(3-3)$ & $3(3-3)$ & $3(3-3)$ & $3(3-3)$ & $3(3-3)$ \\
\hline Attention and calculation & $1(0-4)$ & $1.5(0-4)$ & $2(1-3)$ & $1(0-2)^{*}$ & $2.5(2-4)$ & $2(1-4)$ \\
\hline Free recall & $0(0-1)$ & $0(0-1)$ & $0(0-0)$ & $0(0-0)$ & $0(0-0)$ & $0(0-0)$ \\
\hline Language & $8(7-8)$ & $8(7-8)$ & $7.5(7-8)$ & $7(7-8)$ & $7.5(7-8)$ & $7(7-8)$ \\
\hline Visual construction & $1(0.3-1)$ & $1(0.3-1)$ & $1(0-1)$ & $0(0-1)$ & $1(0-1)$ & $1(0-1)$ \\
\hline MMSE, total score & $18(16-21)$ & $20(18.3-21)^{\mathrm{a}}$ & $18(17-19)$ & $17(15-21)^{\mathrm{a}}$ & $21(17-23)$ & $19(15-22)$ \\
\hline \multicolumn{7}{|l|}{ Neurocognitive domain } \\
\hline \multicolumn{7}{|l|}{ Memory: } \\
\hline RAVLT & $22(13-26)$ & $21.5(15.5-25)$ & $21(16-25)$ & $17(15-24)$ & $19(18-24)$ & $19(15-20)$ \\
\hline \multicolumn{7}{|l|}{ Working memory: } \\
\hline Forward Digit Span & $5(3-6)$ & $5.5(4-6)$ & $4(4-5.3)$ & $5.5(4-6)$ & $5(4-7)$ & $5(4-6)$ \\
\hline Backward Digit Span & $2(2-3)$ & $3(2.3-3)$ & $3(2-3)$ & $3(2-3)$ & $3(2-4)$ & $3(2-3)$ \\
\hline
\end{tabular}

Median and range are provided unless otherwise indicated. ${ }^{*}$ : intra group difference $(p<0.05)$. $^{\text {a }}$ between group difference $(p<0.05)$. Abbreviation: MMSE, score: Mini-Mental State Examine, score 0 to 30 with higher score indicating better global cognition; Orientation, score 0 to 10 ; Registration, score 0 to 3; Attention and calculation, score 0 to 5; Free recall, score 0 to 3; Language, score 0 to 8; Visual construction, score 0 to 1; RAVLT: Rey Auditory Verbal learning Test, score 0 to 75 with higher score indicating better memory; Digit span (Forward and backward), score 0 to 9 with higher score indicating better working memory direct or indirect

stress. No adverse event induced by the training program including muscle aches was reported.

\section{Discussion}

This randomized study has compared the effect of CAT and IAT in seniors with mild to moderate AD. These two training programs conducted on two sessions per week over 9 weeks did not demonstrate significant changes in plasma BDNF response and were not associated with enhancement in participants' cognitive performance in this specific population. Compared to controls, CAT and IAT were however effective to

Table 4 Comparison of QoL-AD composite scores, before and after the interventions in different groups

\begin{tabular}{|c|c|c|c|c|c|c|}
\hline \multirow[t]{2}{*}{ Item QoL-AD } & \multicolumn{2}{|c|}{ Continuous training group, $n=14$} & \multicolumn{2}{|c|}{ Interval training group, $n=17$} & \multicolumn{2}{|c|}{ Control group, $n=21$} \\
\hline & Pre-training & Post-training & Pre-training & Post-training & Pre-intervention & $\overline{\text { Post-intervention }}$ \\
\hline (1) Physical health & $2(2-3)$ & $3(2-3)$ & $2(2-3)$ & $3(2-3)$ & $2(2-3)$ & $3(2-3)$ \\
\hline (2) Energy & $3(2-3)$ & $3(2-3)$ & $3(2-3)$ & $3(3-3)$ & $2(2-3)$ & $3(2-3)$ \\
\hline (3) Mood & $2(2-3)$ & $3(2-3)^{*}$ & $3(2-3)$ & $3(2-3)$ & $2(2-3)$ & $2(2-3)$ \\
\hline (4) Living situation & $3(3-3)$ & $3(3-3)$ & $3(3-3)$ & $3(3-3)$ & $3(2-3)$ & $3(3-3)$ \\
\hline (5) Memory & $2(1-3)$ & $2(2-2)$ & $2(2-2)$ & $2(2-3)$ & $2(1-2)$ & $2(2-2)$ \\
\hline (6) Family & $3(2-3)$ & $3(3-3)$ & $3(3-3)$ & $3(3-3)$ & $3(3-3)$ & $3(2-4)$ \\
\hline (7) Marriage & $3(3-4)$ & $3(3-4)$ & $3(2-3)$ & $3(2-3)$ & $3(2-3)$ & $3(2-3)$ \\
\hline (8) Friends & $3(2-4)$ & $3(3-3)$ & $3(3-3)$ & $3(2-3)$ & $3(3-3)$ & $3(2-3)$ \\
\hline (9) Self & $3(2-3)$ & $3(3-3)$ & $3(2-3)$ & $3(2-3)$ & $3(2-3)$ & $3(2-3)$ \\
\hline (10) Ability to do chores & $3(2-3)$ & $3(2-3)$ & $3(2-3)$ & $3(2-3)$ & $2(2-3)$ & $2(2-3)$ \\
\hline (11) Ability to do things for fun & $3(2-3)$ & $3(2-3)$ & $3(2-3)$ & $3(2-3)$ & $2(2-2)$ & $2(2-3)$ \\
\hline (12) Money & $2(2-3)$ & $3(2-3)^{*}$ & $2(2-3)$ & $3(2-3)$ & $2(2-3)$ & $3(2-3)$ \\
\hline (13) Life as a whole & $3(2-3)$ & $3(3-3)$ & $3(2-3)$ & $3(2-3)$ & $3(2-3)$ & $2(2-3)$ \\
\hline Total score & $34(32-36)$ & $36(34-37)^{* a}$ & $34(32-35)$ & $34(32-36)$ & $32(29-34)$ & $32(29-36)^{a}$ \\
\hline
\end{tabular}

Median and range are provided unless otherwise indicated. ${ }^{*}$ : intra group difference $(p<0.05){ }^{{ }^{a}}$ : between group difference $(p<0.05)$ QOL-AD: Quality of Life in Alzheimer's Disease, total score 13 to 52 with higher score indicating better quality of life 
improve aerobic fitness parameters and functional capacities with globally no significant difference between them. Better QoL was also reported but only in those engaged in CAT group. This study demonstrated a good adherence rate $(94.2 \%)$ for both trainings; no serious adverse events and a good tolerance as previously reported by others were measured [57-59].

Previous studies reported a significant increase in peripheral BDNF level after aerobic training in seniors [54]. Albeit globally negative, the present study is, to the best of our knowledge, the first that has investigated a comparative impact of two different types of aerobic-type training (i.e. CAT vs. IAT) on plasma BDNF levels in the specific population of seniors with mild to moderate $\mathrm{AD}$. These findings give however raise to different hypotheses to explain the highly heterogeneous variation in the response to aerobic-type training but also to social and cognitive stimulation as considered in the CG. The workloads we programmed for CAT and IAT were based on a percentage of $\mathrm{HR}_{\max }$ as reference value and the participant's physical capacity to perform a maximal effort during IMET. It has been observed that aerobictype training at a fixed intensity leads to interindividual inhomogeneous metabolic responses [60]. Thus, our method based on global recommendations aiming to improve and maintain health in older adults may not have been sufficiently intense in some participant to induce a significant effect on plasma BDNF production $[24,28$, 61]. Several additional factors can however influence the basal synthesis of BDNF at the individual level such as genetic variation, metabolic disorders, and/or inflammatory process and hence the BDNF response to aerobictype training [62]. For example, some authors consider $\mathrm{AD}$ as a metabolic disorder mediated by insulin-resistance at the brain level [63]. The impaired glucose utilization resulted from the accumulation of amyloid plaques combined with, the increased oxidative stress and low grade inflammation, contribute to create a vicious circle that progressively induce and alters cerebral insulin sensitivity and neuronal survival $[63,64]$. Acting as a regulatory pathway, plasma BDNF synthesis could be thus upregulated in some people with $\mathrm{AD}$ in order to try to counteract and compensate the insulin resistance and neuronal loss, independently of the illness severity and associated treatments [65-68]. The exploratory analysis of the plasma BDNF level conducted in the present study has shown that non-responders had a higher level of plasma BDNF compared to responders at baseline. They also elicited a change towards a decrease in their plasma BDNF levels after training. While it is not possible to clearly attribute the reduction of plasma BDNF level among non-responders to a greater signalization and uptake by the central nervous system after endurance training [15], one possible underlying mechanism would be that BDNF retrogradely crosses the blood-brain barrier to promote the neuronal survival [69-71]. Similar observations and hypotheses have been stated by Dougerthy et al. in pre-clinical stages of $\mathrm{AD}$ [72]. This study reported a decrease trend in BDNF levels after 6 months of aerobic exercise that was greater and significant among oldest patients. In the present study, the small sample size and the resulted poor powerful has certainly contributed to limit the ability to detect significant difference in BDNF response.

After aerobic-type training or interactive sessions for CG, no change in MMSE, RAVLT and digit span scores was measured despite variations in plasma BDNF levels (i.e. responder or non-responders). This may suggest that plasma BDNF level is probably not a useful marker for cognitive status, as mentioned by previous studies $[73,74]$. It could be also suggested that exists a delayed response between change in BDNF level and improvement in cognitive performance.

Several systematic reviews described aerobic-type training in $\mathrm{AD}$ has a light but heterogeneous benefit on patients' cognition and memory capacities [75-77]. The reasons would be that a minimal duration, frequency and intensity in a short program duration be necessary, to bring about changes in global cognition [76, 78]. For example, Kemoun et al. after 15 weeks of walk (3-weekly, 60 -min by session) found an improvement in global cognition while $\mathrm{Yu}$ et al. reported not any change in $\mathrm{AD}$ patients after 6 months of practice at the rate of 2-weekly 45-min sessions $[79,80]$. Another reason would be that multimodal training (i.e., combined aerobic training and strength training) could lead about greater improvement in cognitive function (i.e., memory, executive function, global cognition) and structural brain reserves mediated by more neurological mechanism (e.g., promoting insulin growth factor-1 and vascular endothelial growth factor) than aerobic training alone [76, 77, 81].

Although the present results did not reveal a positive impact on the BDNF response and cognitive performance, the two training protocols provided enough intensity, frequency, and duration to significantly improve volunteers' aerobic fitness and functional capacities. It is widely agreed that a better aerobic fitness expressed in MET $\left(1 \mathrm{MET}=3.5 \mathrm{ml} \mathrm{O} / \mathrm{kg}^{-1} / \mathrm{min}^{-1}\right)$ or maximal oxygen uptake $\left(\mathrm{VO}_{2 \max }\right.$ or $\left.\mathrm{VO}_{2 \text { peak }}\right)$ is associated with lower risk of all-cause mortality, reduced cardiovascular risk factor and useful to maintain functional independence in performing activities of daily life [82-84]. Compared to controls; the increase in METs resulted from CAT (+ $14.3 \%)$ and IAT $(+22.7 \%)$ were in the line with the results reported by Sobol et al. [85]. The authors found an increase by $+13 \%$ in $\mathrm{VO}_{2 \text { peak }}$ after 16 weeks of moderate to high intensity aerobic exercise $\left(70-80 \% \mathrm{HR}_{\max }\right)$ in mild to moderate $\mathrm{AD}$. The possible reasons explaining 
the observed improvement would be that an optimal intensity for moderate to maximal aerobic fitness benefits in seniors (i.e., between 70 and $86 \%$ of $H^{2} R_{\max }$ ), regardless of aerobic training modality, would be needed [27, 86]. It is also known that $\mathrm{AD}$ is likely to reduce the functional abilities, with reduced walking speed which may, in turn, lead to progressive loss of functional autonomy and dependency [37, 87]. The lengthening of distance walked in 6MWT measured in participants of the CAT and IAT was of similar extend to which reported by Venturelli et al. and in other studies conducted in patients with AD [88-90]. This also confirms the functional benefits of endurance training in seniors with $\mathrm{AD}$.

Apart from physical and mental health, QoL is also an important component factor to be taken into account when taking care of $\mathrm{AD}$ patients [91]. Compared to controls, the beneficial impact on QoL after CAT evokes the key role of aerobic training to favor social interaction and to improve mood and self-esteem [92, 93]. The present findings are consistent with those previously reported [25]. For example, Abd El-Kader et al. showed that 2 months of moderate aerobic exercise improved all SF-36 subscale scores and mood of AD patients [94]. However, the improvement of QoL-AD score was not significant after IAT. QoL-AD composite integrates caregiver score, which can be negatively influenced by caregiver's burden and patient's behavioral symptom repercussion [42]. These are factors we did not evaluate. Thus, we cannot conclude that IAT could not have any benefit on patients' QoL.

Our study has several limitations. Apart from the very small sample size that limit our power to detect significant difference, we cannot formally exclude the positive impact of information sessions acting as social and cognitive stimulation on plasma BDNF synthesis thus masking the possible benefit of aerobic-type training [95]. The intensities programmed in CAT and IAT could have lacked precision to favor homogeneous responses on plasma BDNF production. We cannot also exclude that participants were committed in additional unrecorded physical exercise outside the program which could also be a confounding factor that affected the results. Other limitations include unknown group difference in presence of genetics factors and which could influence the BDNF synthesis such as BDNF gene polymorphism [53, 96].

\section{Conclusion}

This study shows that 9 weeks of CAT and IAT failed to induce significant plasma BDNF response and improve cognitive performance while equally effective to enhance aerobic fitness and functional capacities in senior with mild to moderate AD. CAT had also a beneficial impact on QoL. The highly heterogeneous plasma BDNF response measured among participants suggest the importance of future studies to consider potential confounders and modulator of plasma BDNF production, such as, BDNF polymorphism and other genetic variants. In addition, further researches are also needed to determine whether peripheral plasma BDNF reflect central BDNF in the particular situation of AD.

\section{Supplementary information}

Supplementary information accompanies this paper at https://doi.org/10 1186/s11556-019-0234-1.

Additional file 1. : Detail of analysis of plasma BDNF levels

Additional file 2. : Characteristics of "Responders" and "No responders" 'by group

Additional file 3. : QoL-AD scores, patient and caregiver, in different groups, before and after intervention

\section{Abbreviations}

6MWT: 6-min walking test; AD: Alzheimer's disease; ADL: Activity of Daily Life; Aß: Amyloid-ßeta; BDNF: Brain Derived Neurotrophic Factor; BMl: Body Mass Index; BP: Blood pressure; CAT: Continuous Aerobic Training; CG: Control Group; DBP: Diastolic Blood Pressure; GDS: Geriatric Depressive Symptoms scale; HR: Heart Rate; IADL: Instrumental Activity of Daily Life; IAT: Interval Aerobic Training; IMET: Incremental Maximal Exercise Tests; HR max: Maximal Heart Rate theoretical; HR peak: Maximal Heart Rate; $M_{E} T_{s}$ : Maximal Metabolic Equivalent of Task; MMSE: Mini Mental State Examination; MTP: Maximal Tolerated Power; QoL: Quality of Life; QoL-AD: Quality of Life of Alzheimer Disease; RAVLT: Rey Auditory Verbal Learning Test; SBP: Systolic Blood Pressure

\section{Acknowledgments}

We would like to thank all the participants and their caregivers who have invested themselves as best as possible. We would also like to thank all the member of the team of the Department of Research (University Hospital Center of Martinique), as well as Delor Regine and Dr. Remi Bellance (The Caribbean reference center for rare neuromuscular and neurologic diseases CeRCa) for their involvement in the project. We also thank Gina Josiane and all the team member of the Association Caribéenne pour le Bien Etre des Personnes Agées (A.C.B.E.P.A) for their help in coordinating the MARAE project.

\section{Author's contributions}

L.E participated in the design of the study, conducted the study, contributed to data analysis and interpretation, and to the writing of the manuscript. T.V participated in the design of the study, contributed to data interpretation and to the writing of the manuscript. S.M participated in the design of the study and analyzed data. A.G.V supervised the collection of data and contributed to writing of manuscript. N.O.L supervised the collection of data. R.N critically revised the manuscript. L.J.C supervised the collection of data and contributed to the writing of manuscript. J.L.F participated in the design of the study, conducted the study, contributed to data interpretation and to the writing of the manuscript. P.O.L critically revised the manuscript and contributed to the writing of the manuscript. All authors meet the criteria for authorship stated in the Uniform Requirements for Manuscripts Submitted to Biomedical Journals. All authors read and approved the manuscript.

\section{Author's information}

Not applicable.

\section{Funding}

This project was funded by the A.C.B.E.P.A for the transportation of participants; we received funds from an internal research project of the university hospital center of Martinique. 


\section{Availability of data and materials}

The datasets used and/or analyzed during this study are available from the corresponding author on reasonable request.

\section{Ethics approval and consent to participate}

All procedures performed in this study involving human participants were in accordance with the ethical standards of the institutional and/or national research committee and with the 1964 Helsinki declaration and its later amendments or comparable ethical standards. This experimental protocol was approved by the local ethic committee for the protection of persons SOUTH-WEST and OVERSEAS III - France; approval received in April 2015 (2015-A00567-42-www.cpp-soom3.u-bordeaux2.fr). This study was approved by the national agency for the safety of medicines - France; approval received in May 2015 (150248B-31) and was registered on the ClinicalTrials.gov website (NCT02968875).

\section{Consent for publication}

Not applicable - but written informed consent was obtained from all individual included.

\section{Competing interests}

None of the above listed authors has any conflicts of interests to declare for the present manuscript.

\section{Author details}

${ }^{1}$ Research Laboratory Mitochondria, Oxidative stress and muscle resistance (MSP, EA-3072), Department of Physiology, Faculty of Medicine, Strasbourg University, Résidence La Yole, bat. B L'Etang Z'abricot, 97200 Strasbourg, France. ${ }^{2}$ Department of geriatric, University Hospital, Strasbourg, France. ${ }^{3}$ Methodology and biostatistics Unit (DRCI), University Hospital Centre of Martinique, Fort de France, France. ${ }^{4}$ The Caribbean reference center for rare neuromuscular and neurologic diseases (CeRCa), University Hospital Centre of Martinique, Fort de France, France. ${ }^{5}$ Department of Functional Exploration and Non-Invasive Cardiology, University Hospital Centre of Martinique, Fort de France, France. ${ }^{6}$ Department of cardiology, University Hospital Centre of Martinique, Fort de France, France. ${ }^{7}$ Department of Geriatric and Gerontology, University Hospital Centre of Martinique, Fort de France, France. ${ }^{8}$ Clinic of Montchoisi, Lausanne, Switzerland.

\section{Received: 25 March 2019 Accepted: 29 December 2019} Published online: 06 January 2020

\section{References}

1. Shah H, Albanese E, Duggan C, Rudan I, Langa KM, Carrillo MC, et al. Research priorities to reduce the global burden of dementia by 2025 . Lancet Neurol. 2016;15(12):1285-94.

2. Hyman BT. The neuropathological diagnosis of Alzheimer's disease: clinicalpathological studies. Neurobiol Aging. 1997;18(4 Suppl):S27-32.

3. Harwood RH, Sayer AA, Hirschfeld M. Current and future worldwide prevalence of dependency, its relationship to total population, and dependency ratios. Bull World Health Organ. 2004;82(4):251-8.

4. Winblad B, Amouyel P, Andrieu S, Ballard C, Brayne C, Brodaty H, et al. Defeating Alzheimer's disease and other dementias: a priority for European science and society. Lancet Neurol. 2016;15(5):455-532.

5. Colcombe SJ, Erickson KI, Raz N, Webb AG, Cohen NJ, McAuley E, et al. Aerobic fitness reduces brain tissue loss in aging humans. J Gerontol A Biol Sci Med Sci. 2003;58(2):M176-80.

6. Jonasson LS, Nyberg L, Kramer AF, Lundquist A, Riklund K, Boraxbekk CJ. Aerobic exercise intervention, cognitive performance, and brain structure: results from the physical influences on brain in aging (PHIBRA) study. Front Aging Neurosci. 2017;8:336

7. Bouaziz W, Schmitt E, Vogel T, Lefebvre F, Leprêtre PM, Kaltenbach G, et al. Effects of a short-term interval aerobic training Programme with active recovery bouts (IATP-R) on cognitive and mental health, functional performance and quality of life: a randomised controlled trial in sedentary seniors. Int J Clin Pract. 2018;73:e13219.

8. WHO | Global recommendations on physical activity for health. WHO. World Health Organization; 2010; IBSN: 9789241599979.

9. Schachter AS, Davis KL. Alzheimer's disease. Dialogues Clin Neurosci. 2000; 2(2):91-100
10. Wang R, Holsinger RMD. Exercise-induced brain-derived neurotrophic factor expression: therapeutic implications for Alzheimer's dementia. Ageing Res Rev. 2018;48:109-21.

11. Loprinzi PD, Herod SM, Cardinal BJ, Noakes TD. Physical activity and the brain: a review of this dynamic, bi-directional relationship. Brain Res. 2013;1539:95-104.

12. Chen W-W, Zhang $X$, Huang W-J. Role of physical exercise in Alzheimer's disease. Biomed Rep. 2016;4(4):403-7.

13. Souza LC, Filho CB, Goes ATR, Del Fabbro L, de Gomes MG, Savegnago L, et al. Neuroprotective effect of physical exercise in a mouse model of Alzheimer's disease induced by $\beta$-Amyloid1-40 peptide. Neurotox Res. 2013;24(2):148-63.

14. Radak Z, Hart N, Sarga L, Koltai E, Atalay M, Ohno H, et al. Exercise plays a preventive role against Alzheimer's disease. J Alzheimers Dis. 2010;20(3): 777-83.

15. Nigam SM, Xu S, Kritikou JS, Marosi K, Brodin L, Mattson MP. Exercise and $B D N F$ reduce $A \beta$ production by enhancing a-secretase processing of APP. J Neurochem. 2017;142(2):286-96.

16. Neeper SA, Gómez-Pinilla F, Choi J, Cotman C. Exercise and brain neurotrophins. Nature. 1995;373(6510):109.

17. Szuhany KL, Bugatti M, Otto MW. A meta-analytic review of the effects of exercise on brain-derived neurotrophic factor. J Psychiatr Res. 2015;60:56-64.

18. Voss MW, Erickson Kl, Prakash RS, Chaddock L, Kim JS, Alves H, et al. Neurobiological markers of exercise-related brain plasticity in older adults. Brain Behav Immun. 2013;28:90-9.

19. Walsh JJ, Tschakovsky ME. Exercise and circulating BDNF: mechanisms of release and implications for the design of exercise interventions. App Physiol Nutr Metab. 2018;43(11):1095-104

20. Wrann CD, White JP, Salogiannnis J, Laznik-Bogoslavski D, Wu J, Ma D, et al. Exercise induces hippocampal BDNF through a PGC-1a/FNDC5 pathway. Cell Metab. 2013;18(5):649-59.

21. Prigent-Tessier A, Quirié A, Maguin-Gaté K, Szostak J, Mossiat C, Nappey M, et al. Physical training and hypertension have opposite effects on endothelial brain-derived neurotrophic factor expression. Cardiovasc Res. 2013;100(3):374-82.

22. Monnier A, Prigent-Tessier A, Quirié A, Bertrand N, Savary S, Gondcaille C, et al. Brain-derived neurotrophic factor of the cerebral microvasculature: a forgotten and nitric oxide-dependent contributor of brain-derived neurotrophic factor in the brain. Acta Physiol. 2017;219(4):790-802.

23. Saucedo Marquez CM, Vanaudenaerde B, Troosters T, Wenderoth N. Highintensity interval training evokes larger serum BDNF levels compared with intense continuous exercise. J Appl Physiol. 2015;119(12):1363-73.

24. Schmolesky MT, Webb DL, Hansen RA. The effects of aerobic exercise intensity and duration on levels of brain-derived neurotrophic factor in healthy men. J Sports Sci Med. 2013;12(3):502-11.

25. Bouaziz W, Vogel T, Schmitt E, Kaltenbach G, Geny B, Lang PO. Health benefits of aerobic training programs in adults aged 70 and over: a systematic review. Arch Gerontol Geriatr. 2017;69:110-27.

26. Vidoni ED, Johnson DK, Morris JK, Van Sciver A, Greer CS, Billinger SA, et al. Dose-response of aerobic exercise on cognition: a community-based, pilot randomized controlled trial. PLoS One. 2015;10(7):e0131647.

27. Huang G, Wang R, Chen P, Huang SC, Donnelly JE, Mehlferber JP. Dose-response relationship of cardiorespiratory fitness adaptation to controlled endurance training in sedentary older adults. Eur J Prev Cardiol. 2016;23(5):518-29.

28. Enette L, Vogel T, Fanon JL, Lang PO. Effect of interval and continuous aerobic training on basal serum and plasma brain-derived Neurotrophic factor values in seniors: a systematic review of intervention studies. Rejuvenation Res. 2017;20(6):473-83.

29. Mackay CP, Kuys SS, Brauer SG. The effect of aerobic exercise on brainderived Neurotrophic factor in people with neurological disorders: a systematic review and meta-analysis. Neural Plast. 2017:4716197.

30. Zoladz JA, Pilc A, Majerczak J, Grandys M, Zapart-Bukowska J, Duda K. Endurance training increases plasma brain-derived neurotrophic factor concentration in young healthy men. J Physiol Pharmacol. 2008;59(Suppl 7):119-32.

31. First MB, Pincus HA. The DSM-IV Text Revision: rationale and potential impact on clinical practice. Psychiatr Serv. 2002;53(3):288-92.

32. American Psychiatric Association., American Psychiatric Association. Task Force on DSM-IV. Diagnostic and statistical manual of mental disorders : DSM-IV. American Psychiatric Association; 1994. 886 p.

33. Shim CY, Ha J-W, Park S, Choi E-Y, Choi D, Rim S-J, et al. Exaggerated blood pressure response to exercise is associated with augmented rise of angiotensin II during exercise. J Am Coll Cardiol. 2008;52(4):287-92. 
34. Albouaini K, Egred M, Alahmar A, Wright DJ. Cardiopulmonary exercise testing and its application. Postgrad Med J. 2007;83(985):675-82.

35. Huggett DL, Connelly DM, Overend TJ. Maximal aerobic capacity testing of older adults: a critical review. J Gerontol A Biol Sci Med Sci. 2005;60(1):57-66.

36. Pescatello LS, Arena R, Riebe D, Thompson PD. ACSM's guidelines for exercise testing and prescription. 9th ed. J Can Chiropr Assoc. 2014;58(3):328.

37. Troosters T, Gosselink R, Decramer M. Six minute walking distance in healthy elderly subjects. Eur Respir J. 1999;14:270-4.

38. Folstein MF, Folstein SE, McHugh PR. Mini-mental state. J Psychiatr Res. 1975;12(3):189-98.

39. Doody RS, Massman P, Dunn JK. A method for estimating progression rates in Alzheimer disease. Arch Neurol. 2001:58(3):449-54.

40. Rey A. L'Examen clinique en psychologie. Paris: PUF; 1970. p. 222.

41. Kiewel NA, Wisdom NM, Bradshaw MR, Pastorek NJ, Strutt AM. A retrospective review of digit span-related effort indicators in probable Alzheimer's disease patients. Clin Neuropsychol. 2012;26(6):965-74.

42. Wolak A, Novella J-L, Drame M, Guillemin F, Di Pollina L, Ankri J, et al. Transcultural adaptation and psychometric validation of a French-language version of the QoL-AD. Aging Ment Health. 2009;13(4):593-600.

43. Logsdon RG, Gibbons LE, McCurry SM, Teri L. Assessing quality of life in older adults with cognitive impairment. Psychosom Med. 1999;64(3):510-9.

44. Clément JP, Nassif RF, Léger JM, Marchan F. Development and contribution to the validation of a brief French version of the Yesavage geriatric depression scale. Encephale. 1997;23(2):91-9.

45. Nelson ME, Rejeski WJ, Blair SN, Duncan PW, Judge JO, King AC, et al. Physical activity and public health in older adults. Med Sci Sport Exerc. 2007; 39(8):1435-45.

46. Yu F, Kolanowski A. Facilitating aerobic exercise training in older adults with Alzheimer's disease. Geriatr Nurs (Minneap). 2009;30(4):250-9.

47. Yu F, Swartwood RM. Feasibility and perception of the impact from aerobic exercise in older adults with Alzheimer's disease. Am J Alzheimers Dis Other Dement. 2012;27(6):397-405.

48. Borg GA. Psychophysical bases of perceived exertion. Med Sci Sports Exerc. 1982;14(5):377-81.

49. Drageset J. The importance of activities of daily living and social contact for loneliness: a survey among residents in nursing homes. Scand J Caring Sci. 2004; 18(1):65-71.

50. Hoaglin DC, Iglewicz B, Tukey JW. Performance of some resistant rules for outlier labeling. J Am Stat Assoc. 1986;81(396):991-9.

51. Zanardini R, Fontana A, Pagano R, Mazzaro E, Bergamasco F, Romagnosi G, et al. Alterations of brain-derived Neurotrophic factor serum levels in patients with alcohol dependence. Alcohol Clin Exp Res. 2011;35(8):1529-33.

52. Kim T-S, Kim D-J, Lee H, Kim Y-K. Increased plasma brain-derived neurotrophic factor levels in chronic smokers following unaided smoking cessation. Neurosci Lett. 2007;423(1):53-7.

53. Lemos JR, Alves CR, de Souza SBC, Marsiglia JDC, Silva MSM, Pereira AC, et al. Peripheral vascular reactivity and serum BDNF responses to aerobic training are impaired by the BDNF Val66Met polymorphism. Physiol Genomics. 2016:48(2):116-23.

54. Dinoff A, Herrmann N, Swardfager W, Liu CS, Sherman C, Chan S, et al. The effect of exercise training on resting concentrations of peripheral brainderived neurotrophic factor (BDNF): a meta-analysis. PLoS One. 2016;11(9): e0163037.

55. Knaepen K, Goekint M, Heyman EM, Meeusen R. Neuroplasticity - exerciseinduced response of peripheral brain-derived neurotrophic factor: a systematic review of experimental studies in human subjects. Sports Med. 2010;40:765-801.

56. Hsiao Y-H, Chang C-H, Gean P-W. Impact of social relationships on Alzheimer's memory impairment: mechanistic studies. J Biomed Sci. 2018;25(1):3.

57. Yu F, Savik K, Wyman JF, Bronas UG. Maintaining physical fitness and function in Alzheimer's disease: a pilot study. Am J Alzheimers Dis Other Dement. 2011;26(5):406-12

58. Yu F, Leon AS, Bliss D, Dysken M, Savik K, Wyman JF. Aerobic training for older men with Alzheimer's disease: individual examples of progression. Res Gerontol Nurs. 2011;4(4):243-50.

59. Frederiksen KS, Sobol N, Beyer N, Hasselbalch S, Waldemar G. Moderate-tohigh intensity aerobic exercise in patients with mild to moderate Alzheimer's disease: a pilot study. Int J Geriatr Psychiatry. 2014;29(12):1242-8.

60. Scharhag-Rosenberger F, Meyer T, Gäßler N, Faude O, Kindermann W. Exercise at given percentages of VO2max: heterogeneous metabolic responses between individuals. J Sci Med Sport. 2010;13(1):74-9.
61. Saucedo Marquez CM, Vanaudenaerde B, Troosters T, Wenderoth N. High intensity interval training evokes larger serum BDNF levels compared to intense continuous exercise. J Appl Physiol. 2015;119(12):1363-73.

62. Balietti M, Giuli C, Conti F. Peripheral blood brain-derived Neurotrophic factor as a biomarker of Alzheimer's disease: are there methodological biases? Mol Neurobiol. 2018;55(8):6661-72.

63. De la Monte SM. Type 3 diabetes is sporadic Alzheimer's disease: minireview. Eur Neuropsychopharmacol. 2014;24(12):1954-60.

64. Marosi K, Mattson MP. BDNF mediates adaptive brain and body responses to energetic challenges. Trends Endocrinol Metab. 2014;25(2):89-98.

65. Burbach GJ, Hellweg R, Haas CA, Del Turco D, Deicke U, Abramowski D, et al. Induction of brain-derived Neurotrophic factor in plaque-associated glial cells of aged APP23 transgenic mice. J Neurosci. 2004;24(10):2421-30.

66. Angelucci F, Spalletta G, di lulio F, Ciaramella A, Salani F, Colantoni L, et al. Alzheimer's disease (AD) and mild cognitive impairment (MCI) patients are characterized by increased BDNF serum levels. Curr Alzheimer Res. 2010:7(1):15-20.

67. Faria MC, Santos Gonçalves G, Rocha NP, Moraes EN, Bicalho MA, Túlio M, et al. Increased plasma levels of BDNF and inflammatory markers in Alzheimer's disease. J Psychiatr Res. 2014;53:166-72.

68. Kimura N, Takahashi M, Tashiro T, Terao K. Amyloid $\beta$ up-regulates brainderived neurotrophic factor production from astrocytes: rescue from amyloid $\beta$-related neuritic degeneration. J Neurosci Res. 2006;84(4):782-9.

69. Pan W, Banks WA, Fasold MB, Bluth J, Kastin AJ. Transport of brain-derived neurotrophic factor across the blood-brain barrier. Neuropharmacology. 1998;37(12):1553-61.

70. Nonomura T, Tsuchida A, Ono-Kishino M, Nakagawa T, Taiji M, Noguchi H. Brain-derived neurotrophic factor regulates energy expenditure through the central nervous system in obese diabetic mice. Int J Exp Diabetes Res. 2001; 2(3):201-9.

71. Lewin GR, Barde Y-A. Physiology of the Neurotrophins. Annu Rev Neurosci. 1996;19(1):289-317.

72. Dougherty RJ, Moon HY, Boots EA, Becke A, Düzel E, Wagner M, et al. The effect of aerobic exercise training on serum BDNF in preclinical Alzheimer's disease. Alzheimers Dement. 2018;14(7):986.

73. SE O, Hobson V, Hall JR, Waring SC, Chan W, Massman P, et al. Brain-derived Neurotrophic factor levels in Alzheimer's disease. J Alzheimers Dis. 2009; 17(2):337-41.

74. O'Bryant SE, Hobson VL, Hall JR, Barber RC, Zhang S, Johnson L, et al. Serum brain-derived neurotrophic factor levels are specifically associated with memory performance among Alzheimer's disease cases. Dement Geriatr Cogn Disord. 2011;31(1):31-6.

75. Cammisuli DM, Innocenti A, Fusi J, Franzoni F, Pruneti C. Aerobic exercise effects upon cognition in Alzheimer's disease: a systematic review of randomized controlled trials. Arch Ital Biol. 2018;156(1-2):54-63.

76. Sanders LMJ, Hortobágyi T, La Bastide-van Gemert S, van der Zee EA, van Heuvelen MJG. Dose-response relationship between exercise and cognitive function in older adults with and without cognitive impairment: A systematic review and meta-analysis. Regnaux J-P, éditeur. PLoS One. 2019; 14(1):e0210036.

77. Öhman H, Savikko N, Strandberg TE, Pitkälä KH. Effect of physical exercise on cognitive performance in older adults with mild cognitive impairment or dementia: a systematic review. Dement Geriatr Cogn Disord. 2014;38(5-6): 347-65.

78. Groot C, Hooghiemstra AM, Raijmakers PGHM, van Berckel BNM, Scheltens $P$, Scherder EJA, et al. The effect of physical activity on cognitive function in patients with dementia: a meta-analysis of randomized control trials. Ageing Res Rev. 2016;25:13-23.

79. Kemoun G, Thibaud M, Roumagne N, Carette P, Albinet C, Toussaint L, et al. Effects of a physical training programme on cognitive function and walking efficiency in elderly persons with dementia. Dement Geriatr Cogn Disord. 2010:29(2):109-14

80. Yu F, Thomas W, Nelson NW, Bronas UG, Dysken M, Wyman JF. Impact of 6month aerobic exercise on Alzheimer's symptoms. J Appl Gerontol. 2015; 34(4):484-500

81. Maass A, Düzel S, Brigadski T, Goerke M, Becke A, Sobieray U, et al. Relationships of peripheral IGF-1, VEGF and BDNF levels to exercise-related changes in memory, hippocampal perfusion and volumes in older adults. Neuroimage. 2016;131:142-54.

82. Arnett SW, Laity JH, Agrawal SK, Cress ME. Aerobic reserve and physical functional performance in older adults. Age Ageing. 2008;37(4):384-9. 
83. Forbes D, Thiessen EJ, Blake CM, Forbes SS, Forbes S. Exercise programs for people with dementia. Sao Paulo Med J. 2014;132(3):195-6.

84. Kodama S, Saito K, Tanaka S, Maki M, Yachi Y, Asumi M, et al. Cardiorespiratory fitness as a quantitative predictor of all-cause mortality and cardiovascular events in healthy men and women. JAMA. 2009;301(19):2024.

85. Sobol NA, Dall CH, Høgh P, Hoffmann K, Frederiksen KS, Vogel A, et al. Change in fitness and the relation to change in cognition and neuropsychiatric symptoms after aerobic exercise in patients with mild Alzheimer's disease. J Alzheimers Dis. 2018;65(1):137-45.

86. Lavie CJ, Arena R, Swift DL, Johannsen NM, Sui X, Lee D-C, et al. Exercise and the cardiovascular system: clinical science and cardiovascular outcomes. Circ Res. 2015;117(2):207-19.

87. Callisaya ML, Launay CP, Srikanth VK, Verghese J, Allali G, Beauchet O. Cognitive status, fast walking speed and walking speed reserve-the Gait and Alzheimer interactions tracking (GAIT) study. Geroscience. 2017:39(2):231-9.

88. Venturelli M, Scarsini R, Schena F. Six-month walking program changes cognitive and $A D L$ performance in patients with Alzheimer. Am J Alzheimers Dis Other Dement. 2011;26(5):381-8.

89. Morris JK, Vidoni ED, Johnson DK, Van Sciver A, Mahnken JD, Honea RA, et al. Aerobic exercise for Alzheimer's disease: a randomized controlled pilot trial. PLoS One. 2017;12(2):e0170547.

90. Miu D, Edin F, Szeto S, Mak Y. A randomised controlled trial on the effect of exercise on physical, cognitive and affective function in dementia subjects. Asian J Gerontol Geriatr. 2008;3(1):8-16.

91. Kahle-Wrobleski K, Ye W, Henley D, Hake AM, Siemers E, Chen Y-F, et al. Assessing quality of life in Alzheimer's disease: Implications for clinical trials. Alzheimer's Dement (Amst). 2017;6:82-90.

92. Williams $\mathrm{CL}$, Tappen RM. Effect of exercise on mood in nursing home residents with Alzheimer's disease. Am J Alzheimer's Dis Other Dementiasr. 2007;22(5):389-97.

93. Zamani Sani SH, Fathirezaie Z, Brand S, Pühse U, Holsboer-Trachsler E, Gerber $\mathrm{M}$, et al. Physical activity and self-esteem: testing direct and indirect relationships associated with psychological and physical mechanisms. Neuropsychiatr Dis Treat. 2016;12:2617-25.

94. Abd El-Kader SM, Al-Jiffri OH. Aerobic exercise improves quality of life, psychological well-being and systemic inflammation in subjects with Alzheimer's disease. Afr Health Sci. Makerere University Medical School; 2016;16(4):1045-1055.

95. Salinas J, Beiser A, Himali JJ, Satizabal CL, Aparicio HJ, Weinstein G, et al. Associations between social relationship measures, serum brain-derived neurotrophic factor, and risk of stroke and dementia. Alzheimer's Dement (New York, N Y). 2017:3(2):229-37.

96. Nascimento CMC, Pereira JR, Pires de Andrade L, Garuffi M, Ayan C, Kerr DS, et al. Physical exercise improves peripheral BDNF levels and cognitive functions in mild cognitive impairment elderly with different bdnf Val66Met genotypes. J Alzheimers Dis. 2015:43(1):81-91.

\section{Publisher's Note}

Springer Nature remains neutral with regard to jurisdictional claims in published maps and institutional affiliations.

Ready to submit your research? Choose BMC and benefit from:

- fast, convenient online submission

- thorough peer review by experienced researchers in your field

- rapid publication on acceptance

- support for research data, including large and complex data types

- gold Open Access which fosters wider collaboration and increased citations

- maximum visibility for your research: over $100 \mathrm{M}$ website views per year

At $\mathrm{BMC}$, research is always in progress.

Learn more biomedcentral.com/submissions 